feet. The body was then probably covered with bark, or skins of animals. Of course the decomposition would go on very rapidiy, and soon no trace remain except the bones and stone implements; then the weapons only. My reason for believing these graves to be "surface" burials is in consideration of the fact that the inhumed weapons and discoloured dirt are only from three to six inches beneath the sod, and this accumulation of soil is that arising from the annual decay of the preceding summer's foliage, coupled with the dust that would naturally gather around any object lying on the ground. The graves such as I have described, too, are only to be found on the slopes of grassy hill-sides that as yet have not been disturbed by the plough. I have never seen such a grave in a ploughed field. Such have been long obliterated; and the relics now found in fields may or may not be those that were buried with their prehistoric owners.

In conclusion, then, seeing that the custom of scalping was not introduced with a knowledge of metals, but preceded it, it is certain that some stone implement was used; and if in a large series of cutting tools we find some that bear resemblance to the modern form, then it is fair to presume that these, and these principally if not wholly, were those formerly in use.

A few words concerning this custom of scalping : is it peculiarly North American? I should be much pleased to learn from some correspondent of NATURE what other races, if any, have the same practice among them. Inasmuch as the Indian custom required of every warrior incontestable proof of his success in battle or in single combat, and considering that a warrior would frequently attack singly some member of a hostile tribe (See Catlin's "North American Indians"), it seems quite a natural method of showing beyond doubt that the clainnant had indeed killed his foe. To produce any portion of another's clothing, or his weapons, would not prove the enemy to have been killed; to produce his scalp shows that such was certainly the case, as the instances of survival after scalping are too few to be considered. Did the custom originate in North America, or was it brought from beyond our borders?

Trenton, New Jersey, Aug. 7

Chas. C. Аввотт

\section{THE SLIDING SEAT FORESHADOWED}

$\widetilde{T}$ is a curious and suggestive fact that nearly all the most ingenious and important mechanical inventions find their representatives in the human frame; consequently, the more we investigate the wonderful mechanism of man's body, the more insight may we expect to get into the principles necessary for the most perfect adaptation of means to ends. Whether we take the lever, the pulley, the inclined plane, the spiral or the curved spring, the arch, or any other simple uncomplicated contrivance adapted with a view to securing strength, or motion, or elasticity, we find it represented in animal mechanics, and arranged sometimes simply, sometimes in a more complex form, in a manner and with a result far more wonderful than ever produced from the most ingenious conceptions, of man's brain.

Of late years the application of the sliding seat to rowing has attracted considerable attention, and although it is beyond the purpose of this paper to consider fully the advantages gained by its application, it will, I think, be necessary to make some reference to what appear to be its principles before we inquire whether it can be traced as existing in certain of the joints.

In the mechanics of rowing we may look upon the hips and spinal column as theoretically a firm, unyielding lever (Fig. 3, S), since it is knit together by the power of the muscles in a man thoroughly trained. The object of this fixedness is evidently to avoid the loss of power and time which would occur if parts had to be strung together preparatory to the pull as the oar catches the water. This spinal lever has its fulcrum at what we call the tuberosities of the ischia $(t)$, or in other words at the points of contact of the body with the seat, and the motive power is placed in the muscles of the back and those of the thigh. The weight to be moved will be acted upon

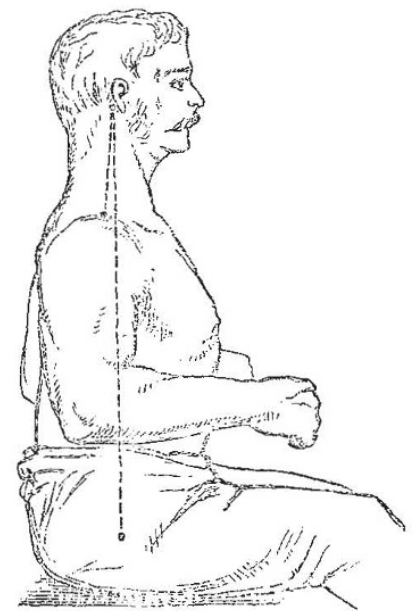

FIG. I - Sitting at rest. Showing tip of shoulder behind the line from mastoid process to hip.

through the arms at the junction of the upper extremities with the spinal lever.

As the body moves forwards, the lever formed by the spine rotates round the tuberosities which constitute the fulcrum, and which slide forward at the same time. The knees are consequently slightly bent or separated. As the oar catches the water the body is brought back to the perpendicular by the action of the muscles of the back and those of the thigh, and the lower end of the lever is at the same time carried bodily back a distance of about eight inches.

The whole principle appears to be that of a sliding fulcrum, and the peculiar result seems to be that a greater reach is given with less bending forward of the body ; for to obtain the same length of stroke the body must either be bent forward at a much more acute angle or carried back beyond the perpendicular. An increased bending

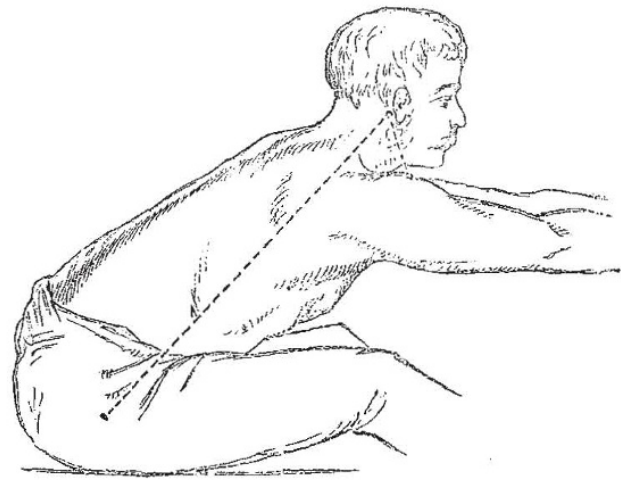

Frg. 2.-Forward movement in rowing, showing tip of shoulder far in front of the line from mastoid process to hip.

forwards, it must be borne in mind, must interfere with the respiration in a long-continued strain as in a race, and therefore with the staying powers of the individual.

If, on the ather hand, the body be carried backwards beyond the perpendicular, the power of recovery is diminished, and far greater work is thrown upon the muscles of the trunk and lower limbs. 
With a sliding seat, therefore, we seem to have a provision for greater range of movement at the distal end of the lever. In the upper extremity it seems to me we find the same principle at work, and if so it is curious that we should have adopted as a novelty or an invention what nature has provided us with in other points, that we should apply to the lower extremities in rowing the same principle that already exists in connection with the upper, and is brought into action perhaps especially in rowing, and that this should have been done unknowingly.

The bony framework of the upper limb is connected with that of the trunk at only one point, the inner or sternal end of the collar-bone, and it is round this point that movement occurs. The greatest freedom of motion, however, takes place at the shoulder-joint, and as this joint is, moreover, at the apparent junction of the free limb with the body, the movements here are generally looked into to the exclusion of those at the junction of the collar-bone and breast-bone. But the importance of the latter will at once be recognised when it is considered that the collar-bone and shoulders rotate round the upper part of the breast-bone, and according to their length and mobility will move through a larger or smaller arc.

The amount of movement between the extremes of forward and backward positions of the shoulder (Figs. I and 2) can be readily tested, and I have found that the average of several observations on different individuals, taken at the tip of the shoulder, the chest being absolutely fixed, is from six to seven inches; or, in other words, the tip of the shoulder moves backwards and forwards to that extent between the extremes of forward and backward movement.

Similarly in the vertical line a large extent of motion occurs, the difference between the extremes being on the average four inches. Now, when it is noticed that the arm moves at the shoulder-joint with an extraordinary amount of facility, and that its chief motions as a mochanical appendage to the trunk occur in that articulat:on, we are led to look upon the arm, fore-arm, and hand as a compound lever, working with its one end free and the other rotating in the socket of the shoulder-joint.

In the lower extremity we also find the compound lever working with one end somewhat similarly in a socket. In the case of the upper, however, the socket is a movable onc, slipping backwards and forwards freely with the limb and strangely increasing its range of motion; still capabie of being fixed firmly in position by the superficial muscles of the back. But in the lower extremity the socket is fixed, and there is no provision for sliding, since strength rather than range of motion is wanted, and where greater range of motion is needed, as in rowing, there a blind application of the principle found in the upper extremity has been only recently effected.

I have referred only to the sliding fulcrum at the shoulder as seen on both sides equally, and as is best exemplified in the position of the arms in rowing, when however the whole trunk also moves; but it must be borne in mind that a still further sliding of the fulcrum is constantly taking place when one hand alone is used, for the chest is also turned towards the object to be reached, by rotating and flexing the spine. The advantage of the vertical motion is seen in such actions as bell-ringing, weight-lifting, \&c. Moreover it must be noticed that when the lever forming the arm is raised from the side to a right motion at the shoulder-joint, and that subsequently the upward motion occurs in the collar-bone, since the top of the shoulder checks the further movement of the arm upwards. There is in connection with the lower extremity a somewhat similar mechanical arrangement, which is not however brought into play so fully as in the upper. The sockets of the hip-joints can be brought forward by a rotation of the spine. This is especially noticeable in those who are prevented from using their feet freely, where therefore the elasticity and spring which are so wonder- fully provided in the foot are lost, and the length of stride is obtained by the utmost use of mechanical advantages commonly unused in connection with the hip. Ploughmen and labourers whose feet are cased in unyielding clogs walk from the hips, or in other words they slide the fulcrum forwards by rotating the spine, whereby they gain a larger stride.

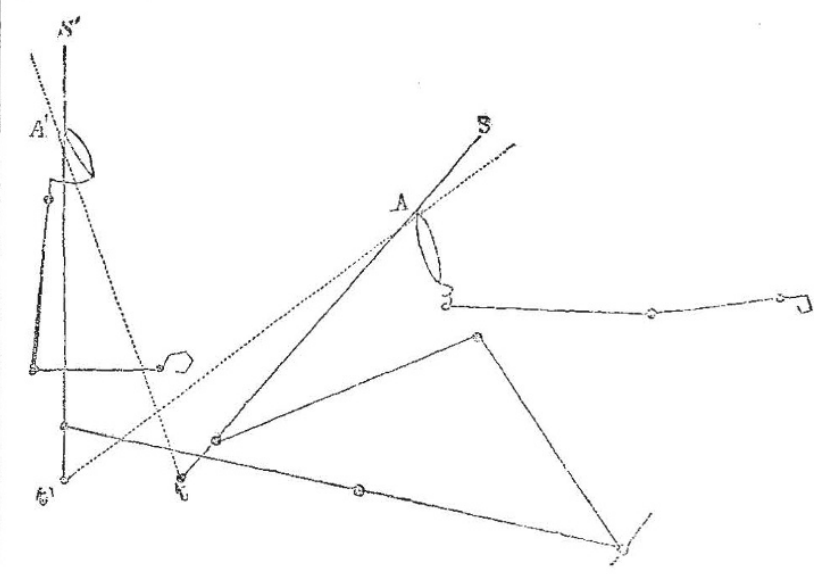

FIG. 3.-Diagram to show sliding-seat action at the shoulders. In the forward position the arm is thrown forward so that the shoulder is about three to four inches in front of the spinal line S A t. In the backward position the same point is about one to two inches behind the same line $s^{\prime} A^{\prime} t^{\prime}$, the whole movement occurring at the stemo clavicular articulation. The sliding of the tuberosities of the ischia backwards in this movemeni is equal to a bout eight inches $\left(t\right.$ to $\left.t^{\prime}\right)$. The dotted lines show the degree of forward or backward movement of the body which would be necessary to gain the same range of arm-movement, if the tuberosities were fixed and no sliding were used.

Such then are some of the curiosities of animal mechanics seen in our wonderful framework, and the subject would repay us in interest as well as in usefulness if studied more by those who are concerned in mechanics generally.

St. Thomas's Hospital

W. W. WAGSTAFFE

\section{THE BRITISH ASSOCIATION}

Bristol, Tuesday Night

UR meeting has nearly run its course, and may so far be pronounced a great success. Brilliant weather has been added to hospitality and to skilful direction, and has produced a generaliy harmonious result. We may certainly expect that the Association, not less than the Bristol people, will desire a repetition of the visit within somewhat fewer than forty years.

Partly owing to the comparative weakness of the President's voice, and partly to the deficient acoustic properties of Colston's Hall, the President's address was not quite so successful as it might otherwise have been. Even Prof. Tyndall had to strain his voice considerably in order to be well heard. Perhaps the most forcible ideas left on the mind by Sir John Hawkshaw are his patience and caution, his dislike for taking leaps in the dark, and his eager desire to take steps in advance when the way can be seen with tolerable clearness. His modesty in not referring to any of his own great achievements, when pertinent references might have been made, was very noticeable. Prof. Tyndall, in his admirable opening address, spoke as follows :-

"It is my privilege to introduce to you as your president for the coming year Sir John Hawkshaw, a name celebrated throughout the world for the practical application to works of the greatest magnitude of some of these sciences which it is the function of this Association to foster and advance. In him, I doubt not, you will have a wise and prudent head, a leader not likely to be caught 